

\section{ÍNDICE}

\section{ÁMBITOS PERSONALES PERSONAL ÁMBITOS}

Crisis de Venezuela: Análisis y perspectivas según los titulares de la prensa argentina, española y china

Venezuela's crisis: Analysis and perspectives in the headlines of Argentine, Spain and China press

Hui Feng Liu

Tratamiento informativo de la violencia de género: asesinatos de mujeres. Análisis de la agencia EFE

Informative treatment of gender violence: murders of women. Analysis of the press agency EFE Rosa Rodríguez Cárcela, Agustín López Vivas

MONOGRAFICOS MONOGRAPHS

Presentación Monográfico. El universo transmedia de los medios de comunicación universitarios: acción dentro y fuera del aula en la sociedad postdigital

Antonia Isabel Nogales-Bocio, Ángels Álvarez villa

El papel transformador de la radio universitaria en materias teóricas ajenas a la comunicación

The transformative role of college radio in theoretical subjects outside communication

Miguel Ángel Díaz Monsalvo

La radiodifusión universitaria: acción discursiva radiofónica para la divulgación de la ciencia University Radio Broadcasting: Radiophonic Discursive Action for the Science Popularization Jorge Sadi Durón, Joel Zapata Salazar

El uso corporativo de Instagram en las universidades privadas españolas. Estudio comparativo de treinta y cinco universidades

The corporate use of Instagram in spanish private universities. Comparative analysis of thirty-five private universities 
La radio universitaria como herramienta de inclusión social: OndaCampus en contextos como la cárcel y barrios desfavorecidos

The university radio as a tool for social inclusion: OndaCampus in contexts like the prison and disadvantaged neighborhoods

Leonor Real Adame, Daniel Martín-Pena, Macarena Parejo Cuéllar

Hacer radio universitaria en la era de YouTube: uso de la plataforma de vídeos a demanda en el contexto mexicano

Make college radio in the age YouTube: use of video on demand platform in the Mexican context Marina Vázquez Guerrero

\section{ARTÍCULOS ARTICLES}

O impresso e o digital nos modelos de negócios de jornais locais: uma análise do Sermos Galiza

The press and digital in business models from local media: Analysis of newspaper Sermos Galiza

Giovanni Ramos

Publicidad y cáncer en la prensa escrita (1903-1912)

Advertising and cancer in the written press (1903-1912)

Laura Almudéver-Campo, Ramón Camaño-Puig

Game rules vs. fandom. How Nintendo's Animal Crossing fan-made content negotiates the videogame meanings

Las reglas del juego vs. el fandom. Cómo el contenido hecho por fans de Nintendo Animal Crossing negocia los significados del videojuego

Jose A. Moreno

La comedia de situación y su análisis textual: evolución de los elementos constructivos del formato

The sitcom and its textual analysis: evolution of the constructive elements of the format

Darío Martín Sánchez

Análisis del discurso emocional de Donald Trump en la campaña electoral de $\mathbf{2 0 1 6}$ Analysis of Donald Trump's emotional speech on the 2016 election campaign 
Innovar, comunicar y transformar (en) la Universidad

Innovate, communicate and transform (at) the University

María Sofía Bernat

288-292

Transparencia en los medios: Un requisito imprescindible para medir la rentabilidad social en radio y televisión

Transparency in the media: An essential requirement to measuresocial profitability in radio and television

Amanda Salazar

Los estudios feministas en comunicación: representación de las mujeres en la revolución tecnológica

Feminist studies in communication: representation of women in the technological revolution 


\title{
El uso corporativo de Instagram en las universidades privadas españolas. Estudio comparativo de treinta y cinco universidades
}

The corporate use of Instagram in spanish private universities. Comparative analysis of thirty-five private universities

\author{
María Alcolea Parra, Universidad Udima, \\ Vía de Servicio A-6, 15, 28400 Collado Villalba, Madrid \\ maria.alcolea@udima.es | Orcid: https://orcid.org/0000-0001-5460-4289 \\ Dolores Rodríguez Barba, Universidad Complutense, \\ Avda. Complutense, s/n Ciudad Universitaria 28040, Madrid \\ lolar@ucm.es | Orcid: https://orcid.org/0000-0001-8437-5536 \\ Víctor Núñez Fernández, Universidad Udima, \\ Vía de Servicio A-6, 15, 28400 Collado Villalba, Madrid \\ victor.nunez@udima.es | Orcid: https://orcid.org/0000-0002-6359-5959
}

DOI: http://dx.doi.org/10.12795/Ambitos.2020.i47.06

\begin{abstract}
Resumen
La lucha por atraer alumnos e investigadores de todas las partes del mundo y la aparición de nuevas instituciones privadas ha forzado a las universidades privadas españolas a utilizar herramientas de comunicación globales, así como a realizar planes
\end{abstract}


estratégicos de marketing en redes sociales para poder vender a la institución de la forma más eficaz. Instagram ha irrumpido en las universidades como un terremoto, pues en tan solo 9 años ha conseguido que el $100 \%$ de las universidades privadas posea un perfil institucional en dicha red caracterizada por la importancia de la imagen. El objetivo del presente artículo consiste en analizar el papel efectivo de la red social Instagram en las universidades privadas españolas tanto a nivel morfológico como de contenido. Para ello, se han analizado los perfiles de Instagram de las 35 universidades privadas españolas en un periodo de 15 días ( 1 al 15 de junio 2019) a través de una investigación descriptiva (observando lo que realizan las universidades en Instagram) y analítica (análisis de las variables seleccionadas a través de las herramientas de medición Metricool y Ninjalytics). Los resultados revelan una clara implicación de las instituciones en los últimos años, no obstante la investigación refleja que los gabinetes de comunicación no le destinan los recursos necesarios para una buena gestión y planificación de la herramienta que desemboque en acciones tangibles. Así mismo, se ha demostrado que el uso que las universidades hacen del perfil oficial de Instagram es beneficioso para la institución y deben reforzar sus estrategias.

\begin{abstract}
The challenge to attract students and researchers from all over the world and the emergence of new private institutions has forced Spanish private universities to use communications tools and strategic marketing plans in social media in order to promote the institution in the most effective way. Instagram constitutes one of the most useful social media tools in this regard. In the last 9 years, Instagram has achieved that $100 \%$ of Spanish private universities have created an institutional profile characterized by the importance of the image and the high chance to customize customize posts. The aim of this study is to analyze the social networking profile of Instagram in all the private universities in Spain both at the morphological and content levels. To that aim, Instagram profiles of the 35 universities have been analyzed in a period of fifteen days (June 1 to $15,2019)$ through both descriptive research (by monitoring what universities undertake on Instagram) and analytical research (the analysis of the selected variables by means of Metricool and Ninjalytics measurement tools). The results of this study reveal a clear implication of the academic institutions in daily publications, despite universities do not allocate the necessary resources to make a successful management of Instagram. Likewise, it has been shown that the use that universities make the official Instagram profile is beneficial for the institution and should therefore reinforce its strategies.
\end{abstract}

Palabras clave: Comunicación, universidad privada, Instagram, redes sociales, marketing educativo.

Keywords: Communication, private university, Instagram, social media, educational marketing. 


\section{INTRODUCCIÓN}

\subsection{Presentación del tema investigado y justificación de su estudio}

A causa del crecimiento del número de alumnos y del incremento de titulaciones, se ha producido en España en los últimos años un aumento importante de las universidades privadas. Tal y como demuestra la fundación BBVA, el número de universidades privadas se ha multiplicado por cinco en 20 años-solo en 2019 han surgido 3 nuevas universidades que antes dependían de otras instituciones, se trata de la Escuela de Negocio y Centro Universitario (ESIC) -hasta ahora dependiente de la Rey Juan Carlosla Universidad Internacional Villanueva y el Colegio Universitario de Estudios Financieros (Cunef) -centros adscritos a la Complutense durante más de veinte añosgenerando una gran competencia en el sector educativo (Ruiz, 2019).

Ya en el año 2005, Durán explicaba cómo las universidades públicas y privadas empezaban a competir entre ellas para captar estudiantes y que se matriculasen con anuncios a toda página comenzando así una guerra publicitaria. A día de hoy, existen un total de 35 universidades privadas en España y la hipótesis general de la que partimos es que dichas universidades no invierten todo lo que deberían en departamentos de comunicación, y más particularmente, en redes sociales. Los centros no le otorgan la importancia suficiente a pesar de los cambios producidos en los últimos tiempos y el impacto de las nuevas tecnologías que obligan, de forma necesaria y continua, a revisar las estrategias de comunicación en un entorno más digital. Es decir, actualmente las universidades buscan diferenciarse en un mercado global (LafuenteRuiz-de-Sabando, et al., 2018).

Como afirma María García (2018), "la presencia corporativa de las universidades españolas en los medios sociales es una realidad pero, no es suficiente con crear un perfil corporativo en las redes más populares sino que dicha presencia debe responder a objetivos estratégicos".

Es por ello que el futuro de la estrategia comunicativa de las universidades debe pasar por realizar un planteamiento multicanal y que las universidades privadas deben aprovechar la ventaja que tienen frente a las universidades públicas en el entorno digital (Digital Group, 2018).

Tal y como comentaba García (2018), Internet ha venido a complicar un poco más el panorama universitario, convirtiendo a las universidades en instituciones globales donde los públicos internacionales tienen tanta presencia como los locales.

Las redes sociales pueden otorgar muchas utilidades a las universidades, no solo mantener el contacto con los estudiantes; además, se pueden utilizar como una herramienta para mantener conectados a aquellos alumnos que ya hayan terminado sus 
carreras, para mejorar su imagen de marca a nivel corporativo o, incluso, para que públicos que no conocen la institución se conviertan en conocedores de la misma (Kierkegaard, 2010).

Desde su aparición en la Edad Media, la Universidad ha sido el vehículo de creación y transmisión del conocimiento (Aurell, 2015). "En el escenario sociocultural y tecnológico actual encontramos a las universidades como instituciones con una responsabilidad social que cubrir en el contexto de la sociedad y unas necesidades específicas en cuanto a cuestiones comunicativas se refiere" (Rodríguez, García y Cerdá, 2018).

Hoy en día, son miles las universidades que están luchando por conseguir tener a los mejores estudiantes para poder, de esta forma, reforzar el prestigio que tantos años les ha costado conseguir. Con la llegada de la Web 2.0 y los Social Media las Universidades se han convertido en Universidades 2.0 (San Millán, Blanco y Del Arco, 2008).

Dentro de Internet las redes sociales han experimentado un gran crecimiento que sigue en auge según un estudio de Statista (2019) la media de consumo de las redes sociales a nivel global está en 136 minutos al día, destacando Filipinas con un consumo de 252 minutos diarios.

En una revisión preliminar de las redes sociales de las universidades españolas, pudimos advertir que Instagram se había convertido en una red con mucho potencial, por el uso intensivo que de ella hacen los jóvenes. En la actualidad, el 100\% de los centros universitarios privados poseen un perfil en dicha red. El uso era destinado a divulgación de información promocional de la propia universidad, así como para promover iniciativas y generar experiencias en los usuarios. En la tabla 1, se puede observar los perfiles sociales que poseen las universidades privadas españolas, así como los seguidores totales en octubre de 2019, y en verde, la universidad con más seguidores en dicha red. 
Tabla 1

Presencia de las universidades españolas en las redes sociales

\begin{tabular}{|c|c|c|c|c|c|c|}
\hline n. ${ }^{0}$ & UNIVERSIDAD & TWITTER & FACEBOOK & INSTAGRAM & YOUTUBE & LINKEDIN \\
\hline 1 & Cunef & 3203 & 8410 & 2137 & 153 & 14719 \\
\hline 2 & Esic & 24400 & 36923 & 8541 & 7650 & 98868 \\
\hline 3 & IE University & 12100 & 25579 & 9901 & 3800 & 11781 \\
\hline 4 & Universidad Abad Oliva CEU. & 4857 & 14195 & 1708 & $\mathrm{x}$ & 10863 \\
\hline 5 & Universidad Camilo José Cela & 16700 & 20373 & 4280 & 1080 & 45442 \\
\hline 6 & Universidad Cardenal Herrera - CEU & 13000 & 31102 & 7043 & 4450 & 24966 \\
\hline 7 & Universidad Católica de Avila & 1 & 6316 & 2216 & 569 & 11417 \\
\hline 8 & $\begin{array}{l}\text { Universidad Católica de Valencia San } \\
\text { Vicente Mártir }\end{array}$ & 11100 & No es visible & 6152 & 2310 & 23248 \\
\hline 9 & $\begin{array}{l}\text { Universidad Católica San Antonio de } \\
\text { Murcia }\end{array}$ & 33900 & 42079 & 35200 & 44200 & 31078 \\
\hline 10 & Universidad de Alfonso X El Sabio & 6437 & 23299 & 7403 & 1280 & 27587 \\
\hline 11 & Universidad de Antonio de Nebrija & 16100 & 33615 & 11700 & No tiene & No tiene \\
\hline 12 & Universidad de Deusto & 25500 & 18569 & 6127 & 7650 & 73608 \\
\hline 13 & Universidad de Navarra & 45200 & 26253 & 14500 & 17900 & 63985 \\
\hline 14 & Universidad Europea de Canarias & 42900 & 96871 & 18600 & 10400 & 95457 \\
\hline 15 & Universidad Europea de Madrid & 42900 & 96871 & 18600 & 10400 & 95457 \\
\hline 16 & Universidad Europea de Valencia & 42900 & 96871 & 18600 & 10400 & 95457 \\
\hline 17 & Universidad Europea del Atlántico & 2641 & 9891 & 3804 & 1610 & 9489 \\
\hline 18 & Universidad Europea Miguel de Cervantes & 6981 & 5962 & 1968 & 2222 & 17370 \\
\hline 19 & Universidad Fernando Pessoa-Canarias & No tiene & 6293 & 6241 & 10 & No tiene \\
\hline 20 & Universidad Francisco de Vitoria & 11000 & 33212 & 10500 & 1004 & 36822 \\
\hline 21 & Universidad Internacional de Cataluña. & 15400 & 34073 & 5638 & 3420 & 20866 \\
\hline 22 & Universidad internacional de la Rioja & 23100 & 121751 & 11200 & 49900 & 72040 \\
\hline 23 & Universidad internacional de Valencia & 27800 & 250411 & 9345 & 8380 & 19324 \\
\hline 24 & Universidad Internacional Villanueva & 2907 & 3652 & 1910 & 482 & 7030 \\
\hline 25 & Universidad Isabel I & 8670 & 16340 & 2508 & 1840 & 8449 \\
\hline 26 & Universidad Loyola Andalucía & 9331 & 7147 & 2766 & 1,22 & 8039 \\
\hline 27 & Universidad Mondragón & 8600 & 7317 & 2619 & 1850 & 20481 \\
\hline 28 & Universidad Oberta de Cataluña & 33100 & 86328 & 13300 & 22600 & 141110 \\
\hline 29 & Universidad Pontificia de Comillas & 10100 & 13186 & 4429 & $\mathrm{x}$ & 78806 \\
\hline 30 & Universidad Pontificia de Salamanca & 4887 & 6511 & 1573 & 279 & No tiene \\
\hline 31 & Universidad Ramón Llull & 10800 & 2249 & deporte & $\mathrm{x}$ & No tiene \\
\hline 32 & Universidad San Jorge & 3631 & 6828 & 2212 & 862 & 11041 \\
\hline 33 & Universidad San Pablo-CEU & 11100 & 23019 & 4221 & 367 & 63193 \\
\hline 34 & Universidad Udima & 13900 & 30819 & 3685 & 17200 & 27995 \\
\hline 35 & Universidad VIC & 11200 & 11109 & 8039 & 1080 & 17841 \\
\hline
\end{tabular}

Fuente: webs de universidades, redes sociales. Elaboración propia octubre 2019.

Por lo tanto, la gran oportunidad que encontramos en dicha investigación es, por un lado, la falta de estudios sobre las universidades privadas en materia comunicativa, ya que la literatura académica normalmente se centra en las universidades públicas. Como ejemplos, se pueden citar la tesis doctoral de Ángeles Durán (2005), en la que se concluye que solo 22 de las 64 universidades analizadas disponían de un plan de comunicación; y el artículo de Simancas-González y García-López (2017), en el que se observa que la situación sigue muy parecida ya que concluye que más de la mitad de las universidades públicas no tienen un Plan de Comunicación.

Y por otro lado, se torna necesario realizar una investigación sobre la red social Instagram en las universidades privadas españolas como consecuencia de la falta de estudios científicos en materia comunicativa que contengan un análisis de la red social en cuestión. Como ejemplos podemos citar varios estudios como el artículo de Paniagua-Rojano, Gómez-Calderón y Fernández-Sande (2012) en el que analiza las redes sociales Facebook, Twitter, Youtube, Linkedin, Tuenti y hasta Flickr de quince universidades españolas pero no contempla Instagram que ya existía desde 2010 o el texto de Alonso y Alonso (2014) dos años más tarde que analiza los perfiles de 
Facebook y Twitter de siete universidades españolas pero seguimos sin tener ningún dato de Instagram. De la misma forma, Campos, Rivera y Rodríguez (2014) estudiaron la presencia e impacto de las universidades andinas en Facebook, Twitter, YouTube, Google+ y ResearchGate. No es hasta el año 2017 con el artículo de García (2018) que observamos como la red social Instagram se introduce en el ranking de las redes sociales más utilizadas en las universidades españolas ocupando el quinto lugar. Ese año ya contaba con más de 8 millones de usuarios.

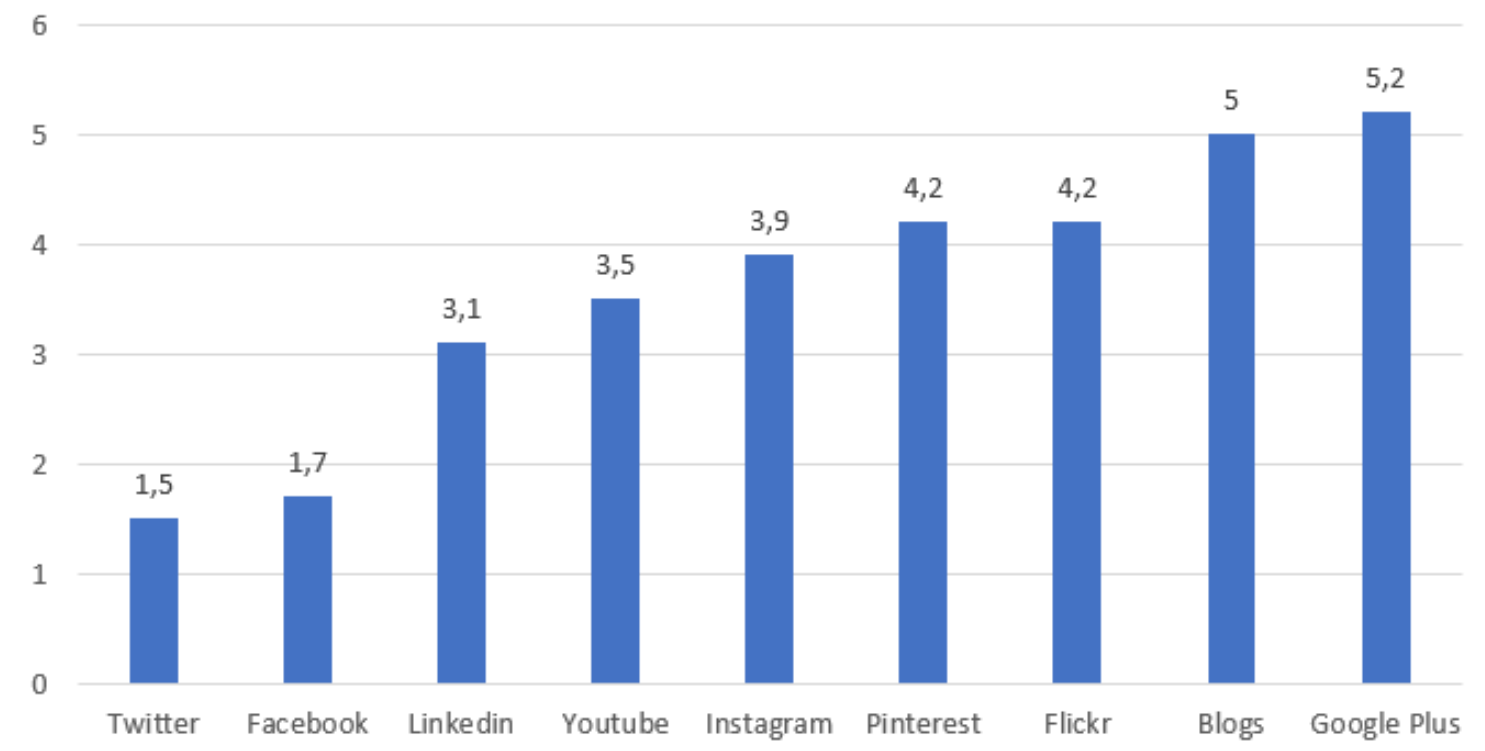

Figura 1. Media de la importancia dada a cada plataforma

Fuente: Alonso, S. y Alonso, M. (2014). Las redes sociales en las universidades españolas. Vivat Academia, (126), 54-62. Elaboración propia.

"Una cuestión relevante era conocer cuáles son las plataformas prioritarias para las universidades españolas" (García, 2018). En la figura 1 se observa cómo en 2017 la plataforma más importante para las universidades españolas es Twitter seguida de Facebook y Linkedln. Es por ello que abordamos este análisis de Instagram como red social en las instituciones académicas privadas, tras constatar su presencia en todas ellas y que ya ocupa el quinto lugar entre las redes más utilizadas.

Hace ya 15 años que nació la primera gran red social global, Facebook, y desde esa fecha el panorama de Internet y de los medios sociales ha avanzado mucho y son numerosas las redes sociales que han ido apareciendo y se han ido alojando en nuestras vidas. No obstante, el caso de Instagram resulta mucho más llamativo, puesto que esta aplicación exclusivamente para smartphones creada en 2010 para compartir fotografías, en solo nueve años ha llegado a superar la cifra de mil millones de usuarios (Kemp, 2019). Pero a pesar de esa evolución tan rápida la comunidad científica parece no haberse dado cuenta de la importancia de este hecho y, es por ello, que encontramos 
numerosas investigaciones sobre Facebook o Twitter, y que las investigaciones realizadas en Instagram en este ámbito escasean en el ámbito hispanohablante, tal y como hemos comentado en párrafos anteriores.

Por consiguiente, el objeto de estudio que determinamos para este artículo es la red social Instagram en las universidades privadas españolas, entendida como instrumento estratégico de comunicación y diferenciador frente a la competencia.

\subsection{Revisión teórica y planteamiento del problema}

A partir de los años ochenta, varios organismos internacionales aconsejaron a algunas instituciones relacionadas con el mundo educativo que agregaran otras actividades a su misión tradicional para poder ser más competitivos (González-Cadena y Coronado, 2018).

Los tiempos han cambiado y, con ello, las nuevas formas de comunicar. La sociedad ha sufrido cambios sustanciales a nivel tecnológico y, como consecuencia, también han variado los medios a través de los que comunicarnos. Habitualmente, nos centramos en estos cambios a nivel social y empresarial, sin ser verdaderamente conscientes de que las redes sociales tienen un alto potencial en el ámbito educativo en general, pero, muy especialmente, en la comunicación de los centros universitarios.

Los alumnos ya no son como antes, ha habido un proceso de transformación en el que se han convertido en millennials, "nativos digitales" (Prensky, 2001), "que privilegian y dedican una gran parte de su tiempo a actividades inherentemente relacionadas con nuevas tecnologías, tales como los videojuegos, el correo electrónico, Internet, los teléfonos móviles y los mensajes instantáneos" (Núñez, Menor y Baeza, 2014) por lo que es necesario ser conocedores de todas estas modificaciones para poder adentrarnos en su día a día de una forma coherente y atractiva, a través de estrategias de comunicación.

Hoy en día, la visibilidad es fundamental y nos lo recuerdan todas las redes sociales existentes. La comunicación de la Universidad hacia la sociedad, no se hace exclusivamente en los medios de comunicación tradicionales, con sus habituales "filtros" informativos. La comunicación es mucho más directa con cada uno de los públicos consumidores, muchísimas veces sin intermediarios y es bidireccional (Simón, 2014).

Flores-Vivar (2009) define las redes sociales como "punto de encuentro, de reuniones de amigos o personas que tienen intereses comunes". Más adelante Xifra (2011) explica que las redes sociales suponen un gran cambio y una oportunidad para las instituciones universitarias al "construir una red personal o profesional en torno a la personalidad de uno mismo" y Almansa-Martínez, Fonseca y Castillo-Esparcia (2013) comentan que "las redes sociales permiten una nueva forma de comunicarse". Las redes sociales otorgan 
mucha libertad al usuario en tanto que cualquier persona puede acceder y compartir contenidos, propios y de otros (Segarra-Saavedra et al., 2018).

Según el estudio anual de redes sociales en España del Interactive Advertising Bureau Spain (2019), "el 85,5\% de los internautas de 16-65 años utiliza redes sociales, lo que representa más de 25 millones usuarios en España. Además, el perfil del internauta que utiliza las redes sociales es muy similar en ambos sexos (hombres $49 \%$ vs mujeres $51 \%$ ) y promedia una edad de 39 años" (Rodríguez, 2019).

Asimismo, el informe de Kemp (2019) Global Digital Overview muestra que hay 3.534 millones de usuarios de redes sociales en el mundo en 2019, con un crecimiento mundial total de 288 millones, es decir, un $9 \%$ más que el año pasado.

Las redes sociales suponen, por lo tanto, en el mundo educativo una nueva herramienta de la que se deben nutrir las universidades para conectarse con los públicos ya que "las redes sociales se han convertido en instrumento ciudadano para difundir y recibir información acerca de temas que consideran de interés social" (Cancelo y Almansa, 2014).

Como se cita en Lacayo-Mendoza y de Pablos-Heredero (2016) "las marcas universitarias tienen ante sí grandes retos a los que hacer frente en los medios sociales ya que son un escaparate desde el cual mejorar la competitividad de las instituciones de enseñanza superior".

Algunos de los desafíos que encuentran hoy las universidades como se cita en Vidal (2013), Cisneros, Olave y Rojas, (2015), García Félix, Conejero y Diez Ruano (2014) y Lobillo (2018), la diversidad, la autonomía, la internacionalización, la adaptación a las nuevas exigencias del mercado laboral, la orientación del potencial estudiante y la incertidumbre que plantea la transformación digital, el desarrollo de la investigación o la necesidad de contribuir a la sociedad (Wang, 2019).

En 2014, Gómez-Calderón y Paniagua-Rojano, realizaron una investigación sobre Twitter en la que concluían lo siguiente:

* El uso que las universidades españolas dan a sus perfiles oficiales en Twitter presenta rasgos uniformes, al menos por lo que a las instituciones más activas en la red se refiere. El tipo de información que suministran atiende de modo preferente a ciertos ámbitos de la actualidad universitaria, en concreto la docencia y la cultura, al tiempo que descuida áreas determinantes en la actividad de cualquier institución de educación superior.

Estos y otros autores solo analizaron la red social Twitter o Facebook que poseían un mayor auge en este período, pero actualmente hay otras redes sociales que han ido 
creciendo y que se otorga indispensable su análisis, como es la red social que ocupa este artículo: Instagram.

De la misma manera, Pérez-Montoro (2014) observó que las universidades se empezaban a preocupar por sus estrategias de difusión de información a través de sus webs institucionales, poniendo en valor a la comunicación.

La universidad no puede ni debe dejar de comunicar tanto internamente como con el exterior, teniendo en cuenta que dicha comunicación no se desarrolla solo mediante sus acciones intencionales de comunicación, sino que la universidad comunica también a través de comportamientos y acciones que tienen lugar en su día a día. Es por ello que en los últimos lustros la comunicación ha ido ganando peso en el seno de la institución universitaria y, a día de hoy, se ve necesario orientar correctamente sus actuaciones comunicativas (De-Aguilera, Farias y Baraybar, 2010).

Tal y como asegura Durán (2005) el corporate aplicado al ámbito universitario no había hecho nada más que empezar y actualmente es una de las grandes estrategias de los gabinetes de comunicación de las universidades, solo que se observa la necesidad de sacarle un partido mucho mayor tal y como hacen las grandes multinacionales.

En definitiva, se puede observar que se ha producido un cambio de paradigma del modelo de comunicación aplicado a la comunicación organizacional y que casi todas las compañías relevantes de nuestro país, han sido conscientes de la importancia de la pertenencia y buen uso estratégico de la red social Instagram.

Centrándonos, por lo tanto, en la red social Instagram, es una forma de comunicación donde los usuarios pueden compartir fácilmente sus actualizaciones al tomar fotos y ajustarlas usando filtros (Rubira, 2013). Creada en el año 2010 por Kevin Sustrom y Mike Krieger (Hu, Manikonda y Kambhampati, 2014), la aplicación de Instagram permite capturar una imagen con el dispositivo móvil y aplicarle numerosos filtros (Ramos, 2015) y ha visto fortalecida su popularidad en los últimos años debido a su fácil y sencillo uso a través de teléfonos móviles (Marcelino y De la Morena, 2014).

Las funcionalidades que caracterizan a dicha red, joven, dinámica, basada en imágenes (el $40 \%$ de los usuarios respondan mejor a la información visual que ante el texto) hacen que Instagram tenga un mayor potencial para la comunicación de las universidades que las funcionalidades que encontramos en otras redes sociales (webescuela.com).

Instagram permite obtener retro-alimentación de forma inmediata $y$, de esta forma, consigue que la universidad obtenga información valiosa sobre sus usuarios, a la vez que una imagen moderna y dinámica que promueve las conexiones con sus principales destinatarios. 
Como afirman Rojas-Torrijos y Panal (2017) algunas de las características de Instagram son el uso de hashtag que "permite reunir información sobre un tema en concreto y llegar de una forma más sencilla al usuario; los "me gustas", que sirven para medir el grado de satisfacción de los seguidores con las publicaciones que se realizan; el texto que puede compartirse junto a la imagen que invita a escribir sobre acontecimientos o noticias; filtros para la edición y mejora de las fotografías, por ejemplo Clarendon, Gringhan, Moon, Lark, Reyes, que dan un aspecto muy mejorado de cada imagen y permite diferenciarse del resto; el vídeo con una duración de 3 a 60 segundos y que se reproduce en bucle, las stories que le otorgan a los usuarios la posibilidad de crear vídeos de 15 segundos, que desaparecen a las 24 horas y los filtros de las stories como por ejemplo Iridescent Glitter, Heart Windows, Golden Glitter, Heart Bloom que permiten subir historias mucho más divertidas y entretenidas para los usuarios; y también los llamados boomerang que son "permite crear pequeños clips de vídeo de apenas un par de segundos que se repiten en bucle" (Instagram, 2019).

Las novedades más importantes de esta plataforma en 2018 y 2019, son la creación de pegatinas gif "cientos de miles de calcomanías móviles que funcionan con GIPHY, la incorporación de enlaces y hashtag de perfil en bio que "se convierten en enlaces en vivo que conducen a una página, hashtag u otro perfil", el nuevo servicio de retratos llamado focus con el que la persona permanece enfocada mientras el fondo se difumina suavemente, el lanzamiento de IGTV, una nueva aplicación para ver vídeos verticales de larga duración diseñado para la forma con la que utilizas el teléfono, la introducción de música en Instagram stories y el uso de pegatinas de preguntas interactivas que permite a tus amigos enviar preguntas para que respondas y puedas conocerlos mejor y la aparición de checkout o pago en instagram que te permite hacer compras sin salir de la plataforma facilitando la compra a los usuarios (Instagram, 2019).

De este modo, Instagram resulta ser una red muy visual para la comunicación corporativa de las universidades. Sobre todo porque se trata de un servicio sin coste a través del cual la universidad puede difundir numerosos contenidos para mejorar su imagen y reforzar así, el contacto con los usuarios. Además, debemos tener en cuenta que en esta red es donde está, sobre todo la gente joven, es decir, el público al que se suelen dirigir las universidades (Howie, 2014).

En 2017 según Rojas-Torrijos y Panal, esta plataforma alcanzó los 700 millones de usuarios activos en el mundo. Al año siguiente tal y como afirma el diario El economista.es "Instagram fue la red social que más creció en España durante 2018 hasta alcanzar los 15 millones de usuarios, lo que representa un 13,13\% más que el año anterior, según la quinta edición del 'Estudio sobre los usuarios de Facebook, Twitter e Instagram en España". 
A principios de 2019 el número de usuarios de redes sociales en todo el mundo creció a casi 3.500 millones, con 288 millones de nuevos usuarios en los últimos 12 meses, lo que significa una penetración del $45 \%$ en todo el mundo (Kemp, 2019). En España ocupa el puesto 14 con 15 millones de usuarios.

Asimismo, si tenemos en cuenta la edad de los perfiles de Instagram esta investigación destaca que "abundan de forma mayoritaria los 'millennials' ya que hasta el $65 \%$ de los perfiles tiene entre 18 y 39 años, lo que supone más de cinco millones en las 50 ciudades más pobladas" (Europa Press, 2019).

En el año 2012, solo el 8,5\% de las universidades privadas españolas incluían en su estrategia comunicativa la red social Instagram. A día de hoy el $100 \%$ de las universidades privadas españolas posee un perfil en Instagram.

En resumen, es indispensable que además de poseer un perfil en Instagram, las universidades privadas españolas posean un Plan Estratégico de Comunicación en el que tenga un papel importante esta red social, y que contemple su uso de forma adecuada a sus objetivos de comunicación.

\subsection{Metodología y posibles limitaciones}

El objeto de estudio de este trabajo se centra en el análisis del perfil de la red social Instagram de 35 universidades privadas españolas a lo largo de un periodo de 15 días comprendido entre 1 y el 15 de junio de 2019. A pesar de todos los cambios que han ido aconteciendo a lo largo de los últimos años a nivel tecnológico, las universidades siguen teniendo un papel relevante en la sociedad. Instagram puede ser una herramienta efectiva para que las universidades puedan desarrollar su función comunicativa en el máximo esplendor con la predominación de la imagen y con especial hincapié en promocionar los contenidos pero creando comunidad de una forma cercana y útil para los usuarios.

Para ello, se ha trabajado con artículos científicos relativamente recientes pero también con obras temáticas más antiguas para poder establecer los orígenes del objeto de estudio. Además, se ha recurrido a monográficos y tesis doctorales que han enriquecido nuestra investigación.

\subsubsection{Hipótesis}

HI 1. Las universidades privadas españolas no están utilizando todo el potencial a nivel comunicativo en la red social Instagram y no realizan publicaciones con contenido específico para dicha red. 
HI 2. Las universidades privadas españolas consideran Instagram como una red importante dentro de la estrategia de comunicación de la empresa pero no destinan los suficientes recursos para gestionarla de una manera adecuada.

\subsubsection{Objetivos}

Este artículo pretende contribuir al conocimiento y la mejora de las estrategias de comunicación llevadas a cabo por las universidades privadas a través de la red social Instagram. Para ello se proponen un objetivo principal y tres objetivos secundarios.

Objetivo principal:

Ol 1. Hacer un estudio cuantitativo y cualitativo de cómo están utilizando las 35 universidades privadas españolas la red social Instagram como herramienta de comunicación institucional y corporativa.

Objetivos secundarios:

Ol 1.1. Analizar el contenido de cada perfil de las 35 universidades privadas españolas.

Ol 1.2. Investigar las técnicas que están utilizando para obtener una mayor difusión, así como el tipo de interacción.

Ol 1.3. Comparar el tipo de contenido (por temáticas) de los 35 perfiles.

Se estima que, al cumplimiento de dichos objetivos, se podrá conocer el estado de la situación de la red social Instagram de las instituciones universitarias contemplando las publicaciones de un periodo de 15 días ( 1 al 15 de junio de 2019, siendo este periodo de exámenes o celebración de graduación para los estudiantes, depende de cada universidad), de las cuentas pertenecientes a las 35 instituciones objeto de estudio, para de esta forma, resaltar el potencial del que disponen dichos centros universitarios en esta red social para llegar a un mayor número de personas a través de una comunicación digital de calidad. Para desarrollar dicho análisis de los perfiles, se han desarrollado los siguientes mapas de variables formales y otros relativos al contenido de los mensajes:

Análisis de la red social Instagram a nivel general de 35 universidades. Contempla las siguientes variables:

- Fecha de creación.

- Seguidores.

- Seguidos.

- Engagement. 
- Media de comentarios.

- Promedio de publicaciones al día.

- Media de likes.

- Cantidad total de publicaciones.

> Análisis de contenido de la red social Instagram 01-06-19/15-06-19:

- Formato (tipo de imagen/vídeo).

- Temáticas.

- Hashtag.

- $\quad \mathrm{N}{ }^{\circ}$ de comentarios.

- N. ${ }^{\circ}$ de "me gustas".

- Reproducciones.

- Mensajes cobertura en vivo.

- Calidad de la imagen (si usa filtros etc.).

- Stories destacados.

\subsubsection{Metodología}

Para la consecución de estos objetivos se llevará a cabo una investigación descriptiva (observando lo que realizan las universidades privadas españolas en Instagram) y analítica (análisis y evaluación de las variables seleccionadas a través de las herramientas de medición Metricool y Ninjalytics). Por lo tanto, el diseño metodológico de la presente investigación tendente a la consecución de dichos objetivos se concreta en dos fases:

1. Revisión general de la literatura existente: análisis previo de su estado, de los cambios que han ido aconteciendo con la aparición de las nuevas tecnologías con el fin de configurar un contexto del estado de la cuestión.

2. Investigación descriptiva y analítica de casos múltiples: se procederá al análisis y la comparación de la red social Instagram de las universidades privadas españolas (35 en total) y las estrategias comunicativas que realizan los centros en dicha red. Para ello, se establecerán dos mapas de variables, uno más genérico y otro más específico para el análisis comparativo de las 35 cuentas universitarias.

Este tipo de análisis permite determinar si existen diferencias significativas entre la red social Instagram que conduzcan a conclusiones objetivas. Para examinar este uso, hemos llevado a cabo un análisis del contenido de la actividad generada en Instagram por las universidades privadas españolas tanto a nivel morfológico como de contenido. $\mathrm{Y}$, de esta forma, hemos determinado cuál es el uso real que las universidades están 
haciendo de esta red social a nivel institucional. En este sentido, se han seleccionado todas las universidades privadas españolas existentes en abril de 2019 , quedando de la siguiente forma (tabla 2):

\section{Tabla 2}

Las universidades privadas españolas en 2019

\begin{tabular}{|c|c|c|c|}
\hline n. ${ }^{\circ}$ & UNIVERSIDAD & FUNDACIÓN & COMUNIDAD AUTÓNOMA \\
\hline 1 & Cunef & 2019 & Madrid \\
\hline 2 & Esic & 2019 & Madrid \\
\hline 3 & IE University & 2008 & Castilla y León (Segovia) \\
\hline 4 & Universidad Abad Oliva CEU. & 2003 & Cataluña (Barcelona) \\
\hline 5 & Universidad Camilo José Cela & 1998 & Madrid (Vallanueva de la Cañada) \\
\hline 6 & Universidad Cardenal Herrera - CEU & 1999 & Valencia (Moncada) \\
\hline 7 & Universidad Católica de Ávila & 1996 & Castilla y León (Ávila) \\
\hline 8 & $\begin{array}{l}\text { Universidad Católica de Valencia San } \\
\text { Vicente Mártir }\end{array}$ & 2003 & Valencia \\
\hline 9 & $\begin{array}{l}\text { Universidad Católica San Antonio de } \\
\text { Murcia }\end{array}$ & 1996 & Murcia \\
\hline 10 & Universidad de Alfonso X El Sabio & 1993 & Madrid (Villanueva de la Cañada) \\
\hline 11 & Universidad de Antonio de Nebrija & 1995 & Madrid (Hoyo de manzanares) \\
\hline 12 & Universidad de Deusto & 1886 & País Vasco (Bilbao) \\
\hline 13 & Universidad de Navarra & 1952 & Navarra (Pamplona) \\
\hline 14 & Universidad Europea de Canarias & 2012 & Canarias (Santa María de Guía) \\
\hline 15 & Universidad Europea de Madrid & 1995 & Madrid (Villaviciosa de Odón) \\
\hline 16 & Universidad Europea de Valencia & 2012 & Valencia \\
\hline 17 & Universidad Europea del Atlántico & 2013 & Cantabria (Santander) \\
\hline 18 & $\begin{array}{l}\text { Universidad Europea Miguel de } \\
\text { Cervantes }\end{array}$ & 2002 & Castilla y León (Valladolid) \\
\hline 19 & Universidad Fernando Pessoa-Canarias & 2014 & Canarias (Las Palmas) \\
\hline 20 & Universidad Francisco de Vitoria & 1993 & Madrid (Pozuelo de Alarcón) \\
\hline 21 & Universidad Internacional de Cataluña & 1997 & Cataluña (Barcelona) \\
\hline 22 & Universidad internacional de la Rioja & 2008 & Logroño \\
\hline 23 & Universidad internacional de Valencia & 2008 & Valencia \\
\hline 24 & Universidad Internacional Villanueva & 2019 & Madrid \\
\hline 25 & Universidad Isabel I & 2011 & Castilla y León (Burgos) \\
\hline 26 & Universidad Loyola Andalucía & 2011 & Andalucía (Sevilla) \\
\hline 27 & Universidad Mondragón & 1997 & País Vasco (Mondragón) \\
\hline 28 & Universidad Oberta de Cataluña & 1994 & Cataluña (Barcelona) \\
\hline 29 & Universidad Pontificia de Comillas & 1890 & Madrid \\
\hline 30 & Universidad Pontificia de Salamanca & 1940 & Castilla y León (Salamanca) \\
\hline 31 & Universidad Ramón Llull & 1990 & Cataluña (Barcelona) \\
\hline 32 & Universidad San Jorge & 2005 & Aragón (Villanueva del Gallego) \\
\hline 33 & Universidad San Pablo-CEU & 1993 & Madrid \\
\hline 34 & Universidad Udima & 2006 & Madrid (Villalba) \\
\hline 35 & Universidad VIC & 1997 & Cataluña (Barcelona) \\
\hline
\end{tabular}

Fuente: webs universidades. Elaboración propia. 


\section{ANÁLISIS Y RESULTADOS}

El análisis realizado de las universidades seleccionadas arrojó que las 35 universidades privadas existentes en España han incluido en su estrategia de comunicación la red social Instagram como canal de comunicación.

Así mismo, se puede observar en la tabla 3 que las universidades con mayor número de seguidores son: la Universidad Católica de San Antonio (UCAM) con 35.200 seguidores, seguida de la universidad Europea con 18.600 y en tercera posición la Universidad de Navarra con 14.500. Este dato es muy importante ya que si no estás creciendo en tu red social es que resulta irrelevante para los usuarios.

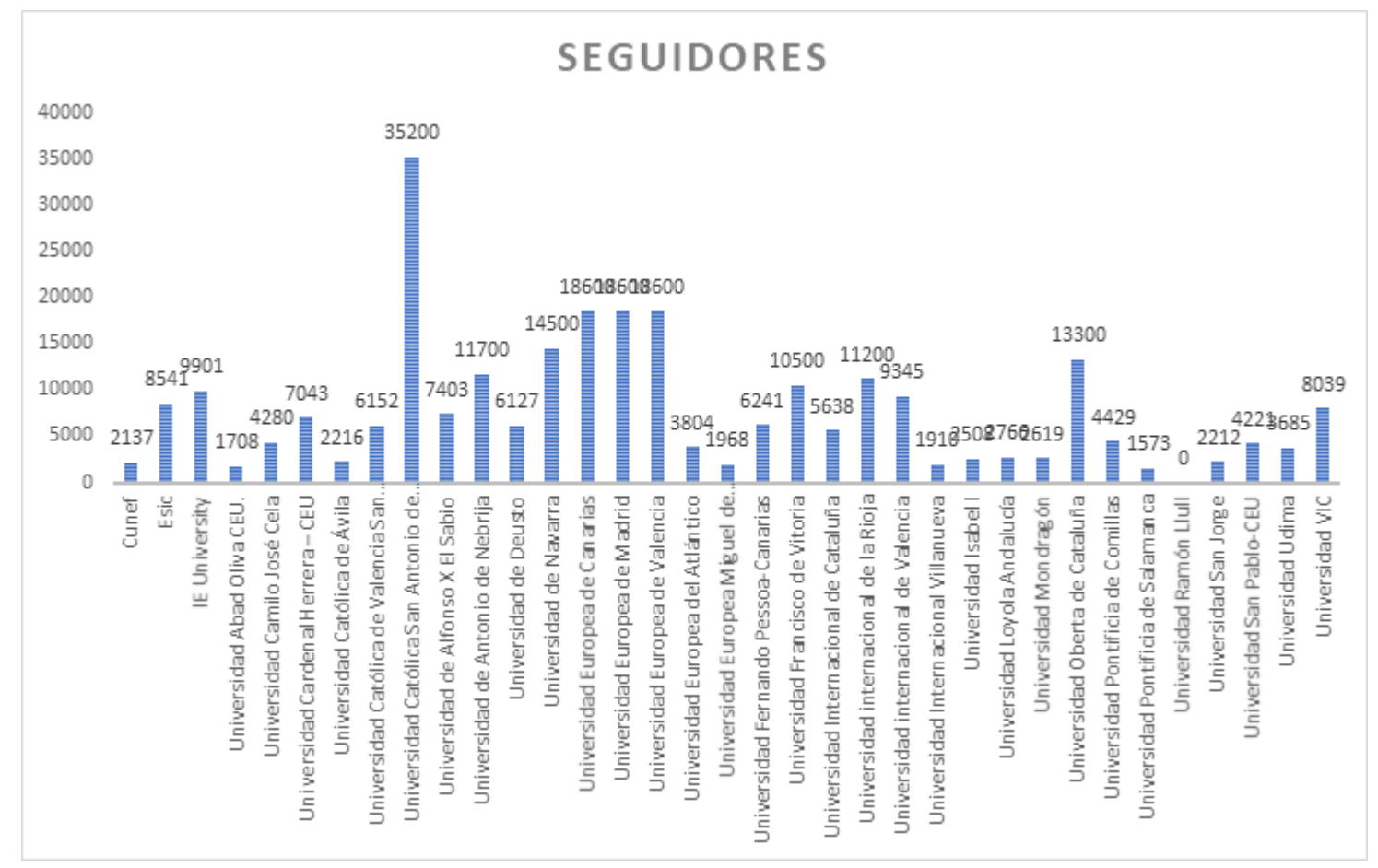

Figura 2. Número de seguidores en las universidades privadas españolas en 2019 Fuente: Metricool. Elaboración propia.

Además, esto indica que, por ejemplo en la UCAM los alumnos eligen el canal de Instagram para estar informados con la universidad. La Universidad Pontifica de Salamanca es la que tiene menos seguidores, seguida de la Universidad Abad Oliva Ceu y, en tercer lugar, de la Universidad Internacional de Villanueva.

Si analizamos el ratio de engagement (gráfico 3) —entendido como número de interacciones recibidas por cada 1000 personas alcanzadas_podemos determinar que la universidad con mayor grado de fidelización es la Universidad Internacional de Villanueva con un $\mathbf{7 2} \%$ de engagement, a continuación se encontraría la universidad 
Abad Oliva Ceu con un $70 \%$ y finalmente estaría CUNEF con un $59 \%$ de engagement. La universidad que tiene el peor dato es la Universidad Oberta de Cataluña (UOC) con un $\mathbf{4 , 8 0 \%}$ seguida de dos que poseen el mismo resultado $8,84 \%$ la Universidad Europea y la Universidad Internacional de Valencia.

Lo que se traduce en que los seguidores de las universidades con mejor engagement son más fieles y utilizan la red social con más frecuencia que las universidades con datos bajos. Además, se observa, que el dato de engagement no tiene nada que ver con los seguidores ya que una universidad como la UCAM tiene muchos seguidores pero la interacción de esos seguidores no llega a $16,14 \%$.

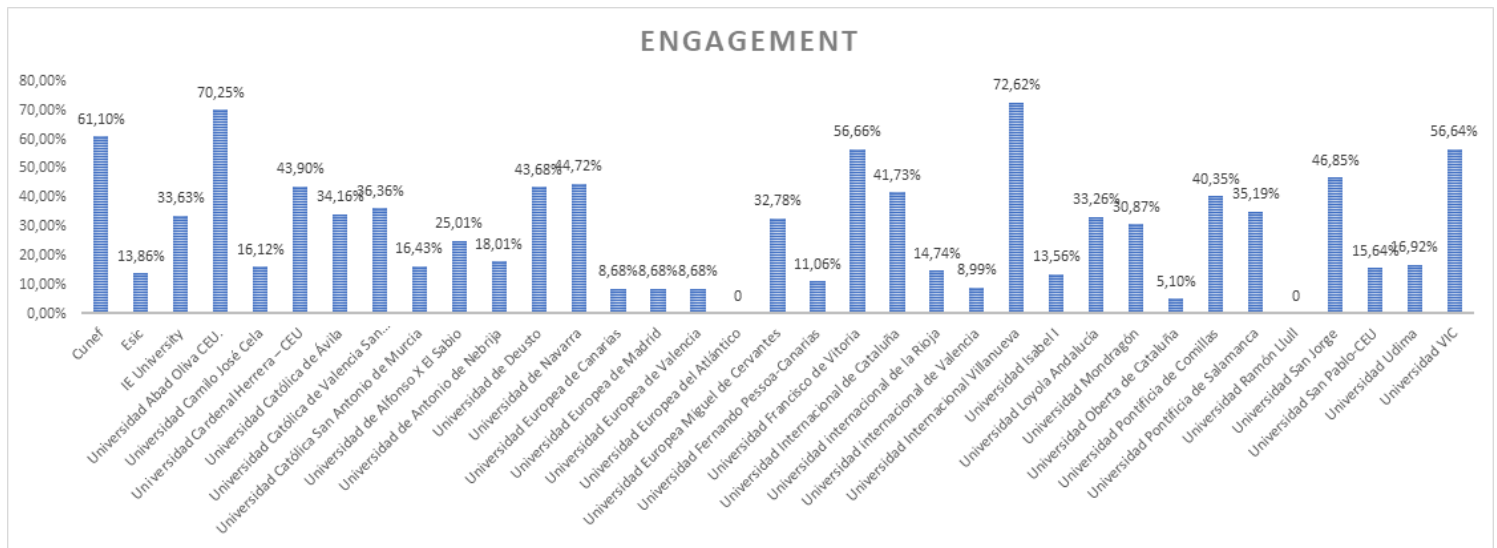

Figura 3. Porcentaje de engagement en las universidades privadas españolas en 2019 Fuente: Metricool. Elaboración propia.

Si tenemos en cuenta la media de likes, es decir, cuántos likes ("me gustas") recibe una publicación, sabremos cómo de popular es nuestro perfil. En el caso que nos ocupa podemos observar en la tabla 5 que la institución con más media de likes es la IE University con una media de 1.770 likes, seguida de la Universidad de Navarra con 600 likes y de la Universidad Francisco de Vitoria con 595 likes. 


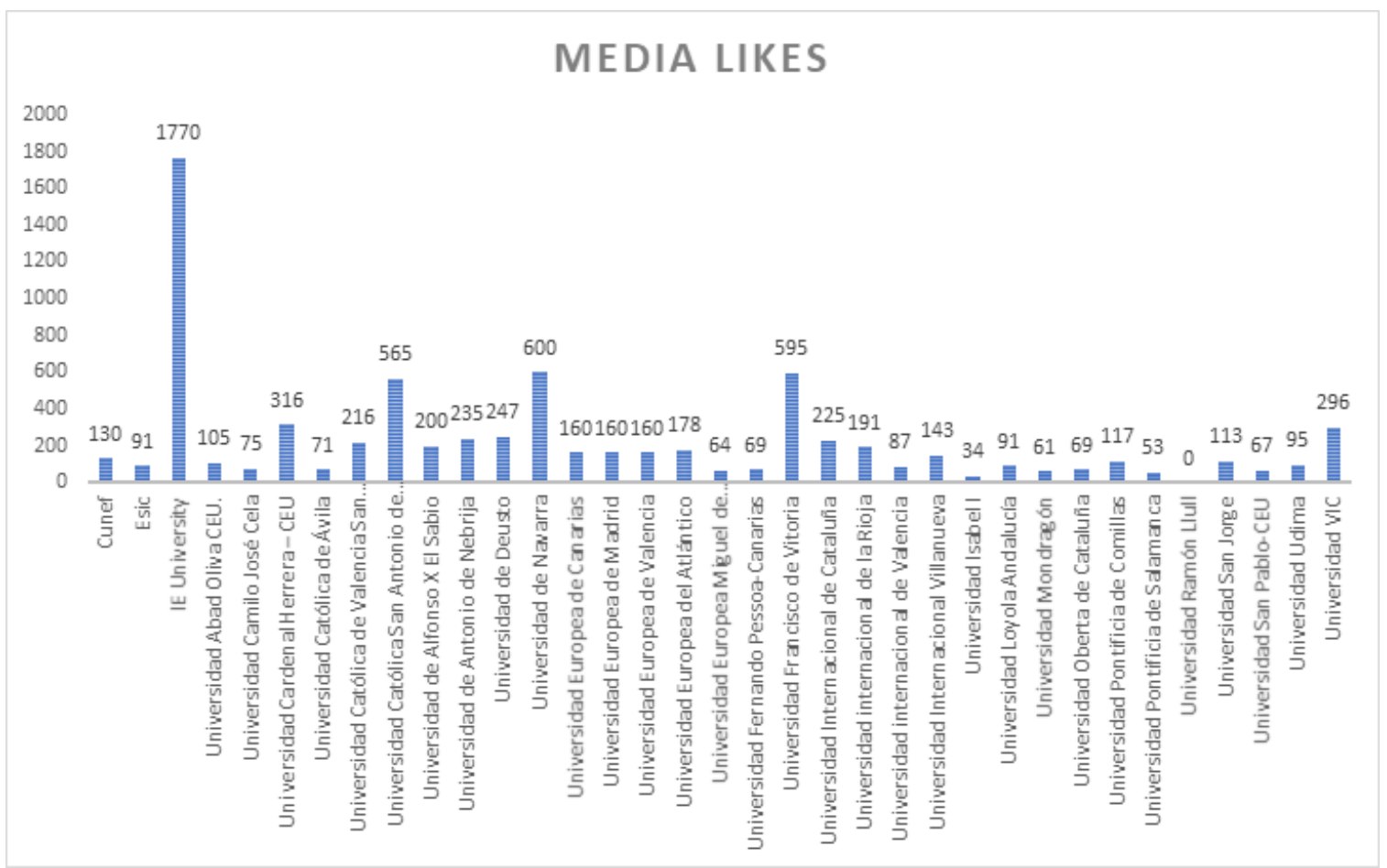

Figura 4. Media de likes en las universidades privadas españolas en octubre 2019 Fuente: Ninjalitics. Elaboración propia.

Otro dato a tener en cuenta es el número de publicaciones que han hecho cada uno de los perfiles de las universidades desde su creación. Esto nos va a indicar el grado de implicación, así como si poseen una constancia y un plan estratégico enfocado a dicha red. Por lo tanto, la tabla 6 hace referencia al número de publicaciones totales, indicando que la universidad que más contenidos publica (posts) es la Antonio de Nebrija con 2.218, seguida de la Universidad Francisco de Vitoria con 1.522 publicaciones y de la Universidad de Vic con 1497 post.

La universidad que menos publica es la Universidad CEU San Pablo con 204 publicaciones desde la creación del perfil seguida de la Universidad a Distancia de Madrid (Udima) con 257 post. 


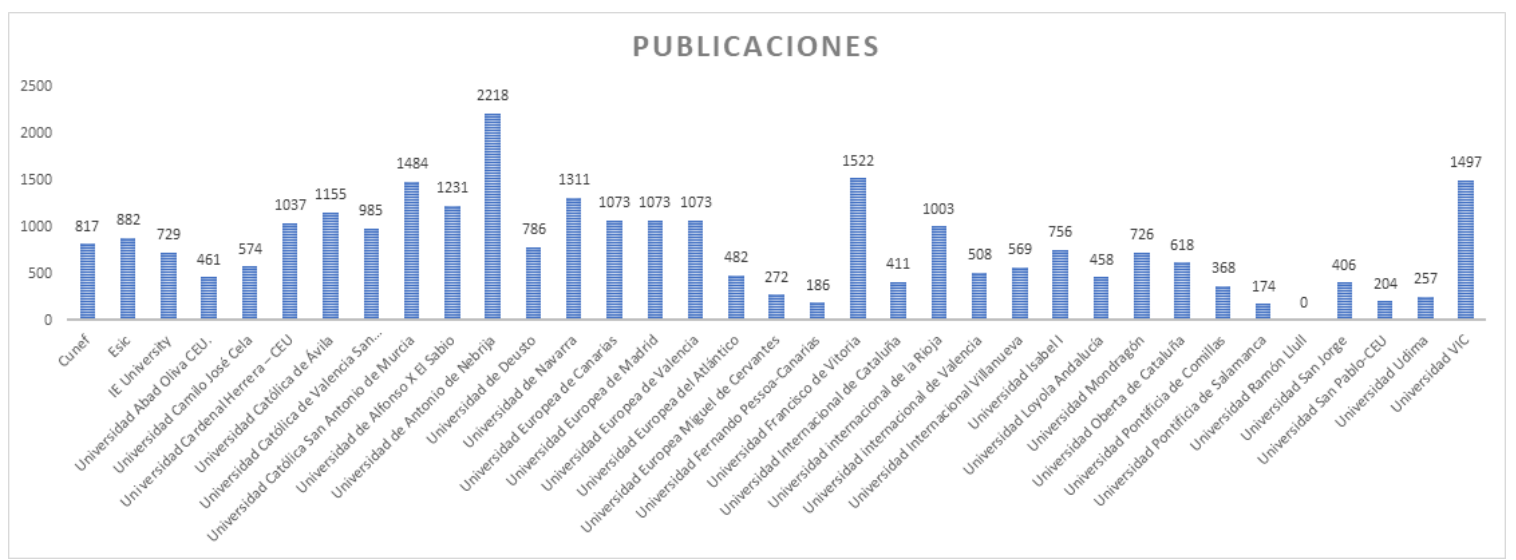

Figura 5. Publicaciones totales en las universidades privadas españolas (octubre 2019) Fuente: Ninjalitics. Elaboración propia.

En referencia a los perfiles que sigue cada universidad (seguidos), todas las universidades parece que siguen la estrategia de no seguir a demasiadas cuentas de Instagram. El caso más llamativo es el de la Universidad Loyola de Andalucía que sigue solo a 34 perfiles y, por contra, la Universidad Europea que sigue a 4.170 perfiles.

Al analizar el contenido de los 35 perfiles en el periodo de quince días (tabla 3), nos percatamos de que la Universidad Alfonso $X$ el Sabio es la más activa ya que ha publicado una media de 26 post en esos 15 días, seguida de la Universidad Antonio de Nebrija con 19 publicaciones y encontramos dos universidades con la media de publicaciones nula, es decir, que no han publicado nada a lo largo de los 15 días de muestra. Se trata de la Universidad de Navarra y de la Universidad de San Jorge, esto determina que no poseen una sistematización de la periodicidad para la red social. Las universidades que menos han publicado son la Universidad Ceu San Pablo con una publicación en toda la quincena y la Universidad a Distancia de Madrid UDIMA, con apenas dos publicaciones.

Las universidades seleccionadas destinaron casi todas sus publicaciones a hablar de sus propias actividades y a divulgar información promocional. Algo poco recomendable si quieren crear una comunidad cercana con información relevante, útil y entretenida para los usuarios.

En general, todas las universidades están limitando el potencial que tiene la red social Instagram en cuanto a formatos y contenidos. La mayoría se centra en la publicación de imágenes y álbumes y, en menor medida, vídeos, por ejemplo estas dos universidades no publican ningún vídeo durante el periodo seleccionado. La UNIR o CUNEF y algunas como ESIC son un ejemplo de la buena calidad de las creatividades y vídeos que publican. 
La interactuación con los seguidores se ha medido por los "me gustas" de tal forma que podremos ver si Instagram como canal de comunicación está funcionando entre los estudiantes. Casi todas las universidades tienen un nivel de interacción bastante alto si hacemos referencia a los likes y un poco bajo si nos referimos a los comentarios.

Tabla 3

Análisis del contenido de Instagram de 35 universidades en un periodo de 15 días

\begin{tabular}{|c|c|c|c|c|c|c|c|}
\hline \multicolumn{8}{|c|}{$(01 / 06 / 19-15 / 06 / 19)$} \\
\hline \multicolumn{8}{|c|}{ Análisis de contenido de Instagram de 35 universidades } \\
\hline Universidad & Cuenta & $\begin{array}{l}\text { Fecha de } \\
\text { creación }\end{array}$ & $\begin{array}{l}\mathrm{N} .{ }^{\circ} \text { de post } \\
\text { publicados }\end{array}$ & Formato & $\begin{array}{c}\mathrm{N} \cdot{ }^{\circ} \text { de } \\
\text { comentarios }\end{array}$ & $\begin{array}{l}\text { N. }{ }^{\circ} \text { de "me } \\
\text { gustas" }\end{array}$ & $\begin{array}{l}\mathrm{N} . \mathrm{de} \\
\text { reproducci } \\
\text { ones }\end{array}$ \\
\hline Cunef & @cunef & $03 / 2014$ & 9 & 7 imágenes y 2 álbumes & 35 & 1260 & $\mathrm{x}$ \\
\hline Esic & $\begin{array}{c}\text { @esicbusiness } \\
\text { school }\end{array}$ & $11 / 2012$ & 5 & $\begin{array}{l}1 \text { imagen, } 1 \text { álbum, } 2 \\
\text { infografias y } 1 \text { video }\end{array}$ & 20 & 456 & 1993 \\
\hline IE University & @ieuniversity & $12 / 2013$ & 6 & $\begin{array}{c}4 \text { imágenes y } 2 \text { infografías } \\
\text { dinámicas }\end{array}$ & 12 & 869 & 2087 \\
\hline Universidad Abad Oliva CEU. & @uaoceu & $03 / 2016$ & 6 & $\begin{array}{c}2 \text { imágenes, } 3 \text { vídeos y } 1 \\
\text { álbum }\end{array}$ & 18 & 246 & 1862 \\
\hline Universidad Camilo José Cela & $\begin{array}{c}\text { @ucjc_univers } \\
\text { idad }\end{array}$ & $10 / 2016$ & 7 & $\begin{array}{c}3 \text { imágenes, } 3 \text { vídeos y } 1 \\
\text { infografia }\end{array}$ & 15 & 299 & 1380 \\
\hline $\begin{array}{l}\text { Universidad Cardenal Herrera - } \\
\text { CEU }\end{array}$ & @uchceu & $06 / 2014$ & 6 & $\begin{array}{c}3 \text { imágenes, } 2 \text { vídeos y } 1 \\
\text { álbum }\end{array}$ & 42 & 1263 & 3781 \\
\hline Universidad Católica de Ávila & @ucavila & $10 / 2014$ & 12 & $\begin{array}{c}7 \text { álbumes, } 3 \text { imágenes, } 1 \\
\text { infogafia, } 1 \text { vídeo }\end{array}$ & 16 & 727 & 836 \\
\hline $\begin{array}{l}\text { Universidad Católica de Valencia } \\
\text { San Vicente Mártir }\end{array}$ & @ucv_es & $04 / 2013$ & 7 & 6 imágenes y 1 infografia & 120 & 1624 & $x$ \\
\hline $\begin{array}{l}\text { Universidad Católica San Antonio de } \\
\text { Murcia }\end{array}$ & $\begin{array}{c}\text { @ucam_univer } \\
\text { sidad }\end{array}$ & $02 / 2014$ & 12 & 12 imágenes & 40 & 7931 & $x$ \\
\hline Universidad de Alfonso XEI Sabio & @uax_ig & $05 / 2015$ & 26 & \begin{tabular}{|c|}
15 imágenes, 1 infografia, \\
8 álbumes, y 2 videos \\
\end{tabular} & 79 & 6006 & 4283 \\
\hline Universidad de Antonio de Nebrija & $\begin{array}{c}\text { @universidad__ } \\
\text { nebrija }\end{array}$ & $10 / 2012$ & 19 & $\begin{array}{c}7 \text { imágenes, } 6 \text { álbumes y } 5 \\
\text { videos }\end{array}$ & 41 & 2549 & 2734 \\
\hline Universidad de Deusto & @udeusto & $10 / 2014$ & 7 & 7 imágenes & 20 & 1951 & $x$ \\
\hline Universidad de Navarra & $\begin{array}{c}\text { @universidadd } \\
\text { enavarra }\end{array}$ & $09 / 2013$ & $x$ & $x$ & $\mathrm{x}$ & $x$ & $x$ \\
\hline Universidad Europea de Canarias & @ueuropea & $07 / 2013$ & 8 & $\begin{array}{c}3 \text { imágenes, } 4 \text { vídeos y } 1 \\
\text { álbum }\end{array}$ & 27 & 1132 & 9741 \\
\hline Universidad Europea de Madrid & @ueuropea & $07 / 2013$ & 8 & $\begin{array}{c}3 \text { imágenes, } 4 \text { vídeos y } 1 \\
\text { álbum }\end{array}$ & 27 & 1132 & 9741 \\
\hline Universidad Europea de Valencia & @ueuropea & $07 / 2013$ & 8 & $\begin{array}{c}3 \text { imágenes, } 4 \text { vídeos y } 1 \\
\text { álbum }\end{array}$ & 27 & 1132 & 9741 \\
\hline Universidad Europea del Atlántico & @uneatlantico & $01 / 2016$ & 5 & $\begin{array}{c}3 \text { imágenes, } 1 \text { álbum y } 1 \\
\text { vídeo }\end{array}$ & 16 & 1081 & 1333 \\
\hline $\begin{array}{l}\text { Universidad Europea Miguel de } \\
\text { Cervantes }\end{array}$ & @uemc & $05 / 2015$ & 5 & 3 infografias y 2 imágenes & 3 & 191 & $x$ \\
\hline Universidad Fernando Pessoa-Canar & @ufpcanarias & $04 / 2017$ & 3 & 2 imágenes y 1 álbum & 2 & 259 & $x$ \\
\hline Universidad Francisco de Vitoria & @ufvmadrid & $02 / 2013$ & 14 & $\begin{array}{c}5 \text { imágenes, } 3 \text { vídeos y } 6 \\
\text { álbumes }\end{array}$ & 69 & 6071 & 10147 \\
\hline $\begin{array}{l}\text { Universidad Intemacional de } \\
\text { Cataluña }\end{array}$ & @uicbarcelona & $09 / 2012$ & 3 & 1 imagen, 1 video, 1 álbum & 14 & 618 & $x$ \\
\hline Universidad intemacional de la Rioja & $\begin{array}{c}\text { @uniruniversid } \\
\text { ad }\end{array}$ & $01 / 2016$ & 3 & $\begin{array}{c}1 \text { imagen, } 1 \text { video, } 1 \\
\text { infografia }\end{array}$ & 28 & 676 & $x$ \\
\hline $\begin{array}{lll}\text { Universidad intemacional de } \\
\text { Valencia }\end{array}$ & $\begin{array}{c}\text { @universidadv } \\
\text { iu }\end{array}$ & $02 / 2017$ & 10 & $\begin{array}{c}3 \text { imágenes, } 4 \text { infografias y } \\
3 \text { álbumes }\end{array}$ & 51 & 514 & $\mathrm{x}$ \\
\hline Universidad Intemacional Villanueva & @villanuevauni & $06 / 2016$ & 3 & $\begin{array}{c}\text { imagen, } 1 \text { infografia y } 1 \\
\text { video }\end{array}$ & 1 & 204 & 507 \\
\hline Universidad Isabel I & $\begin{array}{c}\text { @ui1universid } \\
\text { ad }\end{array}$ & $10 / 2016$ & 17 & $\begin{array}{c}5 \text { imágenes, } 5 \text { infografias, } 6 \\
\text { álbumes y } 1 \text { vídeo }\end{array}$ & 3 & 765 & $x$ \\
\hline Universidad Loyola Andalucia & @loyolaand & $06 / 2015$ & 9 & $\begin{array}{c}4 \text { álbumes, } 3 \text { videoblogs, } 1 \\
\text { vídeo y } 1 \text { imagen }\end{array}$ & 12 & 1055 & 900 \\
\hline Universidad Mondragón & $\begin{array}{c}\text { @munibertsitat } \\
\text { ea }\end{array}$ & $12 / 2014$ & 3 & 3 videos & 6 & $x$ & 3010 \\
\hline Universidad Oberta de Cataluña & $\begin{array}{c}\text { @uocuniversit } \\
\text { at }\end{array}$ & $10 / 2015$ & 8 & $\begin{array}{c}4 \text { vídeos, } 2 \text { imágenes y } 2 \\
\text { infografias }\end{array}$ & 31 & 1695 & 442 \\
\hline Universidad Pontificia de Comillas & @ucomillas & $12 / 2014$ & 14 & $\begin{array}{c}12 \text { imágenes, } 1 \text { infografia y } \\
1 \text { álbum }\end{array}$ & 35 & 2748 & $x$ \\
\hline Universidad Pontificia de Salamanca & $\begin{array}{c}\text { @upsa_salam } \\
\text { anca }\end{array}$ & 12018 & 8 & $\begin{array}{c}3 \text { imágenes, } 2 \text { infografias, } 2 \\
\text { álbumes y } 1 \text { vídeo }\end{array}$ & 8 & 306 & 721 \\
\hline Universidad Ramón Llull & Notiene & No tiene & $x$ & $x$ & $x$ & $x$ & $x$ \\
\hline Universidad San Jorge & $\begin{array}{c}\text { @universidads } \\
\text { anjorge }\end{array}$ & $12 / 2015$ & $\mathrm{x}$ & $x$ & $x$ & $\mathrm{x}$ & $\mathrm{x}$ \\
\hline Universidad San Pablo-CEU & $\begin{array}{l}\text { @universidad_- } \\
\text { ceu_sanpablo }\end{array}$ & $12 / 2016$ & 3 & 3 imágenes & 2 & 292 & $x$ \\
\hline Universidad Udima & $\begin{array}{c}\text { @universidad_ } \\
\text { udima }\end{array}$ & $10 / 2014$ & 2 & 2 infografias & 0 & 26 & $x$ \\
\hline Universidad VIC & @uvic_ucc & $09 / 2013$ & 15 & $\begin{array}{l}9 \text { imágenes, } 2 \text { videos, } 2 \\
\text { infografias y } 2 \text { álbumes }\end{array}$ & 14 & 2007 & 3508 \\
\hline
\end{tabular}

Fuente: Instagram. Elaboración propia. 
En dicho análisis se han detectado los temas sobre lo que más publican y se han dividido en 9 temáticas y son (tabla 4):

1. La promoción de las universidades.

2. Actividad académica.

3. Imágenes de alumnos, testimonios y mensajes motivacionales.

4. Publicaciones dedicadas al profesorado.

5. Visitas o viajes de intercambio.

6. Concursos o juegos.

7. Actividades relacionadas con el deporte.

8. Solidaridad.

9. Noticias o temas de actualidad.

Tabla 4

Análisis de temáticas de Instagram de 35 universidades en un periodo de 15 días

\begin{tabular}{|c|c|c|c|c|c|c|c|c|c|}
\hline \multicolumn{10}{|c|}{$(01 / 06 / 19-15 / 06 / 19)$} \\
\hline \multicolumn{10}{|c|}{ Análisis de temáticas de Instagram de 35 universidades } \\
\hline Universidad & Promoción & $\begin{array}{l}\text { Actividad } \\
\text { académica }\end{array}$ & \begin{tabular}{|c|} 
Imágenes de \\
alumnos, \\
testimonios y \\
mensajes \\
motivacionales
\end{tabular} & Profesorado & $\begin{array}{c}\text { Visitas o } \\
\text { viajes de } \\
\text { intercambi } \\
0 \\
\end{array}$ & $\begin{array}{c}\text { Concursos } \\
\text { /Juegos }\end{array}$ & Deporte & Solidaridad & Actualidad \\
\hline Cunef & & $\bar{X}$ & $x$ & $\bar{X}$ & & $\bar{X}$ & & & \\
\hline Esic & $\mathrm{X}$ & $\mathrm{X}$ & & & & & & & \\
\hline IE University & & & $\mathrm{X}$ & & $\mathrm{X}$ & & $\mathrm{X}$ & & $\mathrm{x}$ \\
\hline Universidad Abad Oliva CEU. & $\bar{x}$ & $\bar{X}$ & $\mathrm{X}$ & & & & & & $\bar{x}$ \\
\hline Universidad Camilo José Cela & $\mathrm{X}$ & $\mathrm{X}$ & & & & & & & \\
\hline Universidad Cardenal Herrera - CEU & & $\mathrm{X}$ & $\mathrm{X}$ & & & & & & \\
\hline \begin{tabular}{|l|l|} 
Universidad Católica de Avila \\
\end{tabular} & $\mathrm{X}$ & $\mathrm{X}$ & $\mathrm{X}$ & $\bar{X}$ & & & $\bar{x}$ & & \\
\hline $\begin{array}{l}\text { Universidad Católica de Valencia } \\
\text { San Vicente Mártir }\end{array}$ & & $x$ & & & & $\mathrm{x}$ & & & $\mathrm{x}$ \\
\hline $\begin{array}{l}\text { Universidad Católica San Antonio de } \\
\text { Murcia }\end{array}$ & $\mathrm{x}$ & $\mathrm{x}$ & $\mathrm{x}$ & & & & $\mathrm{x}$ & & \\
\hline Universidad de Alfonso X El Sabio & $\mathrm{X}$ & $\mathrm{X}$ & $\mathrm{X}$ & & & & $\mathrm{X}$ & & $\mathrm{x}$ \\
\hline Universidad de Antonio de Nebrija & $\mathrm{X}$ & $\bar{X}$ & $\bar{X}$ & & & & & & $\bar{x}$ \\
\hline Universidad de Deusto & OTROS & OTROS & OTROS & OTROS & OTROS & OTROS & OTROS & OTROS & OTROS \\
\hline Universidad Europea de Canarias & $x$ & $x$ & & & & & $x$ & & \\
\hline Universidad Europea de Madrid & $x$ & $\mathrm{X}$ & & & & & $\mathrm{X}$ & & \\
\hline Universidad Europea de Valencia & $\mathrm{X}$ & $\mathrm{X}$ & & & & & $\mathrm{X}$ & & \\
\hline Universidad Europea del Atlántico & & $\bar{X}$ & $\bar{X}$ & & & & $\mathrm{X}$ & & \\
\hline \begin{tabular}{|lll}
$\begin{array}{l}\text { Universidad Europea Miguel de } \\
\text { Cervantes }\end{array}$ & \\
\end{tabular} & & $\mathrm{x}$ & & $\mathrm{x}$ & & & $\mathrm{x}$ & $\mathrm{x}$ & \\
\hline \multicolumn{2}{|l|}{ Universidad Fernando Pessoa-Canarias } & $\mathrm{x}$ & & & & & & & \\
\hline Universidad Francisco de Vitoria & $\bar{x}$ & $\bar{X}$ & $\mathrm{X}$ & & $\bar{X}$ & & & & \\
\hline Universidad Internacional de & & & & & $\mathrm{X}$ & & & $\bar{x}$ & \\
\hline Universidad internacional de la Rioja & $\mathrm{X}$ & $\mathrm{X}$ & & $\mathrm{X}$ & & & & & \\
\hline Universidad internacional de & $\mathrm{X}$ & $\mathrm{X}$ & & & & & & & \\
\hline \begin{tabular}{|l|l} 
Universidad Internacional Villanueva \\
\end{tabular} & & $\mathrm{X}$ & & & & & & $\mathrm{x}$ & \\
\hline Universidad Isabel I & & $\mathrm{X}$ & $\mathrm{X}$ & & & $\mathrm{X}$ & $\mathrm{X}$ & $x$ & \\
\hline Universidad Loyola Andalucía & & $\bar{X}$ & & $\bar{x}$ & $\mathrm{X}$ & & & & \\
\hline Universidad Mondragón & & & $\mathrm{X}$ & & & & & & \\
\hline Universidad Oberta de Cataluña & & $\mathrm{X}$ & $\mathrm{X}$ & & & & & & \\
\hline Universidad Pontificia de Comillas & & $\bar{X}$ & & $\bar{X}$ & & & & & \\
\hline Universidad Pontificia de Salamanca & $\mathrm{X}$ & $\mathrm{X}$ & & & & $\mathrm{X}$ & & & $\bar{x}$ \\
\hline Universidad San Pablo-CEU & & $\mathrm{X}$ & & & & & & & \\
\hline Universidad Udima & $\bar{X}$ & & & & & & & & \\
\hline Universidad VIC & $\mathrm{X}$ & $\bar{X}$ & $\mathrm{X}$ & & $\mathrm{X}$ & $\mathrm{X}$ & & & $x$ \\
\hline
\end{tabular}

Fuente: Instagram. Elaboración propia. 
Cabe señalar la escasa presencia de noticias o temas de actualidad, ya que muy pocas universidades tienen en cuenta la actualidad, un par de ejemplos son IE University que realiza una publicación sobre el día de los océanos, o la Universidad Camilo José Cela que hace una publicación sobre el día del medio ambiente. De la misma forma, llama la atención la ausencia de publicaciones que hagan referencia a temas de investigación tan importantes para todos los centros educativos. Solo encontramos una universidad, Isabel I que ha hecho referencia a la investigación de un profesor en el ámbito de la neurociencia.

Un tema que supone un valor tan importante para la sociedad como la solidaridad tiene escasa presencia en las publicaciones de Instagram de los centros académicos analizados. Solo la Universidad Europea Miguel de Cervantes hace una iniciativa en apoyo para la lucha contra el cáncer. Así mismo, la investigación refleja que las fotografías que cuentan con personas, y sobre todo, en las que se pueden apreciar caras son mucho mejor acogidas en cuanto a interacciones de refiere que si se publican imágenes, por ejemplo de paisajes (Jang, Han, Shih y Lee, 2015).

Por un lado, si hacemos referencia a la media de "me gustas" en la quincena seleccionada, la universidad que registra una interactuación alta en el perfil de Instagram es la UCAM con una media de $\mathbf{6 6 0}$ "me gustas" seguida de la Francisco de Vitoria con 536. Por otro lado, la universidad que menos interacciones de likes tiene es la UDIMA con una media de 28 likes.

Como curiosidad resulta llamativo que dos universidades no publiquen ningún contenido en español. La Universidad de Mondragón publica todos los post en euskera y la Universidad Vic en catalán.

\section{CONCLUSIONES}

El análisis comparado del uso de la red social Instagram por las principales universidades privadas españolas en el periodo de tiempo seleccionado nos ha llevado a varias conclusiones:

Todas las universidades privadas han optado por incluir las redes sociales en sus planes de comunicación y, con ello, también Instagram. Hace 7 años solo un $8,7 \%$ de las universidades privadas españolas poseía un perfil en Instagram, actualmente de las 35 universidades analizadas, el $100 \%$ posee un perfil institucional, salvo la Universidad Ramón Llul, pues es un perfil más deportivo que institucional-por ello no se ha tenido en cuenta en el análisis y no está incluido en su web corporativa-.

En la utilización de la red social Instagram por parte de las universidades españolas, se aprecia que no siguen ningún criterio o parámetro común, sino que poseen una estrategia particular para cada una de ellas y que no le destinan los recursos necesarios 
para una buena gestión y planificación de la herramienta que desemboque en acciones tangibles.

El número de seguidores es fundamental de cara a tener el máximo número de interacciones, así, la universidad UCAM posee 35.200 seguidores y es la universidad con la media más alta de "me gustas" en la muestra analizada. Si tenemos una audiencia mayor tendremos más posibilidades de que aumenten las interacciones.

En este sentido la universidad con más seguidores es la UCAM con 35.200 followers y 23 años de existencia, y la que menos posee es la Universidad Pontificia de Salamanca con 1.573 followers, siendo esta la segunda universidad privada más antigua de nuestro país (79 años). La UCAM ha sabido sacarle todo el potencial a Instagram y conectar con sus estudiantes.

A nivel de contenido Instagram se ha convertido para las universidades privadas españolas en un canal de comunicación del que se puede obtener información de la institución académica, cultural y, en ocasiones, social. Sin embargo, no le otorgan importancia a la publicación de contenido relacionado con la investigación. En el periodo seleccionado solo una universidad, Isabel I,-el 3\% de la muestra analizada— realiza un post sobre el hallazgo de un profesor en el ámbito de la neurociencia.

Así mismo, tener los perfiles creados no garantiza su correcto uso, como es el caso de la Universidad de Navarra o la Universidad de San Jorge, que aun teniendo el perfil no han hecho ninguna publicación, o el caso contrario, la Universidad Alfonso X, que aun siendo la Universidad que más post ha publicado (26 post), no le sirve nada más que para estar en la parte intermedia de la tabla en cuanto a seguidores.

A día de hoy, las universidades no realizan publicaciones con contenido específico para esta red social y no se aprecia una especialización o profesionalización en las publicaciones y tampoco a nivel estético. Las fotografías las suelen publican tal y como lo harían en otra red sin contemplar la posibilidad de utilizar una imagen más cuidada, la misma orientación, calidad y disposición en todas ellas. Además, es bastante reseñable que ninguna universidad publique en Instagram todos los días de la semana.

Como se ha podido observar, los resultados de este artículo confirman que todas las universidades se van adaptando al contexto tecnológico y comunicativo actual, así como la capacidad que posee Instagram para aumentar la presencia online de estos centros académicos y la interacción con los públicos más jóvenes y que, si se realizara un uso más profesional, podría funcionar como una herramienta eficaz de comunicación institucional para las universidades, ayudándolas a posicionarse en un mundo con tanta competencia y ampliar el espectro de público al que se dirigen.

\section{Referencias}


Almansa-Martínez A., Fonseca, O. \& Castillo-Esparcia, A. (2013) "Social Networks and Young People. Comparative Study of Facebook between Colombia and Spain," Comunicar, 20(40), pp. 127-135. doi: 10.3916/C40-2013-03-03.

Alonso García, S. y Alonso García, M. M. (2014) "Las redes sociales en las universidades españolas." Vivat Academia, (126), pp. 54-54. doi: 10.15178/va.2014.126.54-62.

Aurell, J. (2015). "La Universidad en la Edad Media. Reflexiones sobre la identidad de sus orígenes y su continuidad histórica", Revista Empresa y Humanismo, Vol. XVIII, nº1, 141151. Disponible en https://cutt.ly/Ve5eX5K

Campos Freire, F. Rivera Rogel, D. y Rodríguez (2014) "La presencia e impacto de las universidades de los países andinos en las redes sociales digitales" Revista Latina de Comunicación Social, 69, pp. 571-592. doi: 10.4185/RLCS-2014-1025.

Cancelo Sanmartín, M. y Almansa Martínez, A.. (2014). "Estrategias comunicativas en redes sociales. Estudio comparativo entre las universidades de España y México". Historia y comunicación social, 18, 423-435. doi: 10.5209/rev_HICS.2013.v18.44339.

De Aguilera Moyano, M., Farias Batlle, P. y Baraybar Fernández, A. (2012). "La comunicación universitaria. Modelos, tendencias y herramientas para una nueva relación con sus públicos. Revista ICONO14 Revista Científica De Comunicación Y Tecnologías Emergentes, 8(2), 90-124. https://doi.org/10.7195/ri14.v8i2.248

Digital Group (2018). Estudio digital de universidades privadas en España y Portugal 2018. Recuperado de https://bit.ly/2sbNJQF . Fecha de consulta 10/08/2019

Durán Mañes, A. (2005). Nuevas tendencias en la comunicación corporativa. Aplicación a un modelo de'corporate'universitario. Tesis Doctoral Universitat Jaume I. Director Rafael López Lita. Fecha de la defensa: 2005-11-21 ISBN 9788469318706

Europa Press (21 de febrero, 2019). "Instagram la red social que más crece en España en 2018" En elEconomista.es. Recuperado de https://bit.ly/2DR10B0

Flores-Vivar J. M (2009) "New Models of Communication, Profiles and Trends in Social Networks," Comunicar, 17(33), pp. 73-81. doi: 10.3916/c33-2009-02-007.

García García, M. (2018). Universidad y medios sociales. Gestión de la comunicación en la universidad española. Revista Prisma Social, (22), 20-36. Recuperado de https://bit.ly/2RItXqS

Gómez-Calderón, B. J., y Paniagua-Rojano, F. J. (2014). "Las universidades españolas en Twitter: mensajes, contenidos y públicos". Historia y comunicación social, 19, 681-694. https://doi.org/10.5209/rev_HICS.2014.v19.44994

González, M. y Coronado, M. (2018). La tercera misión de las instituciones de educación superior: una lectura desde los teóricos de la globalización y la teoría crítica. Boletín 
Científico INVESTIGIUM de la Escuela Superior de Tizayuca, 3(6). https://doi.org/10.29057/est.v3i6.2950

Howie, J. (2014). Instagram es la red social más utilizada por los jóvenes. Universia, 10 de octubre de 2014. Recuperado de https://bit.ly/2P9ZQal

Hu, Y., Manikonda, L., \& Kambhampati, S. (2014). What we instagram: A first analysis of instagram photo content and user types. In Eighth International AAAl conference on weblogs and social media. Recuperado de https://cutt.ly/se5qZDt

Instituto Valenciano de Investigaciones Económicas (IVIE) (2017). "Evolución de la universidad privada y resultados universitarios. El número de universidades privadas se ha multiplicado por cinco en 20 años y ya forman al $16,4 \%$ de los estudiantes". Ranking 2017: Indicadores sintéticos de las universidades españolas. Recuperado de https://bit.ly/2YtJyvP

Jang, J. Y., Han, K., Shih, P. C., \& Lee, D. (2015). Generation like: comparative characteristics in Instagram. In Proceedings of the 33rd Annual ACM Conference on Human Factors in Computing Systems (pp. 4039-4042). ACM. Doi: 10.1145/2702123.2702555

Kemp, S. (2019). Digital 2019: Global Digital Overview. January, 31 Datareportal. Recuperado de https://cutt.ly/Qe5wwG7

Kierkegaard, S. (2010). "Twitter thou doeth?" Computer Law \& Security Review: The International Journal of Technology and Practice, 26 (6), 577-594. doi: 10.1016/j.clsr.2010.09.002.

Lacayo-Mendoza, A. \& de Pablos-Heredero, C. (2016). "Managing relationships and communications in higher education efficiently through digital social networks: The importance of the relational coordination model". DYNA 83 (195), pp. 138-146. http://dx.doi.org/10.15446/ dyna.v83n195.49296

Lafuente-Ruiz-de-Sabando, A., Zorrilla, P., \& Forcada, J. (2018). "A review of higher education image and reputation literature: Knowledge gaps and a research agenda". European research on management and business economics, 24(1), 8-16. https://doi.org/10.1016/j.iedeen.2017.06.005

Marcelino Mercedes, G.V., \& De la Morena Taboada, M. (2014). Redes sociales basadas en imágenes como herramienta de comunicación museística. Museos y centros de arte Moderno y Contemporáneo de España en Pinterest e Instagram. AdComunica: revista científica de estrategias, tendencias e innovación en comunicación, 8, pp. 139-167. ISSN 2174-0992

Núñez Fernández, V., Menor Sendra, J., y Baeza Román, F. (Coords.) (2014). Educación digital y cultura de la innovación. Fundación Cotec para la Innovación Tecnológica. Col. Innovación Práctica Perspectivas de Futuro. Recuperado de https://bit.ly/2LFmXao

Paniagua-Rojano, F. J., Gómez-Calderón, B. J., y Fernández-Sande, M. F. (2012). "La incorporación de los departamentos de comunicación de las universidades españolas al 
entorno digital. Un análisis cuantitativo" Estudios sobre el mensaje periodístico, 18, 691701. https://doi.org/10.5209/rev_ESMP.2012.v18.40948

Pérez-Montoro, M. (2014). "Políticas universitarias de difusión de la información a través de la propia web institucional". El Profesional de la Información, 23, num. 2, pp. 190-194. doi: 10.3145/epi.2014.mar.12.

Ramos, J. (2015). Instagram para empresas. XinXii. ISBN: 9781301813766

Rodríguez Gómez, A., García Torre, M., y Cerdá Bertoméu, M. (2018). La empresa comunica: protocolo y lenguaje organizacional. Barcelona: Gedisa Editorial.

Rodríguez, S. (2019). "Estudio anual redes sociales en España 2019". Ecommerce news, 6 de junio de 2019. Recuperado de https://bit.ly/33VnxqY

Rojas-Torrijos, J. L., y Panal, A. (2017). El uso de Instagram en los medios de comunicación deportivos. Análisis comparado de Bleacher Report, L'équipe y Marca. Ámbitos: Revista Internacional de Comunicación, 38, 1-19. Recuperado de https://bit.ly/2YGC60C

Rubira, F. (2013). “¿Qué es Instagram y para qué sirve?”. ElConfidencialDigital.com, 24 de junio de 2013. Recuperado de https://bit.ly/34YSJa3 Fecha de consulta, 10/09/2019

Ruiz, R. (2019). "Vía libre a tres nuevas universidades privadas en Madrid". LaRazon.es, 16 de noviembre de 2019 | 15:22 h. Recuperado de https://bit.ly/33YR1nM. Fecha de consulta 10/09/2019.

San Millán Fernández, E., Blanco Jiménez, F. J. y Del Arco Prieto, J. C. (2008). "Comunicación corporativa 2.0 en la Universidad Rey Juan Carlos". Universidad, Sociedad y Mercados Globales. Castro Silva, E. J. y Díaz de Castro, F. J. (Coord.), pp. 394-408. Asociación Española de Dirección y Economía de la Empresa (AEDEM) International Conference, Salvador de Bahía 2008. Disponible en https://bit.ly/2Pbkg2H

Segarra-Saavedra, J., Martínez-Sala, A. M., y Monserrat-Gauchi, J. (2019). Planificación estratégica de la comunicación integrada. Razón y Palabra, 22(3_102), pp. 152-178. Recuperado de https://bit.ly/2rriwt4

Simancas-González, E. y García-López, M. (2017). "Gestión de la comunicación en las universidades públicas españolas". El profesional de la información, 26(4), pp. 735-744. doi: 10.3145/epi.2017.jul.17

Simón Onieva, J. E. (2014). "El uso de las Redes Sociales en el ámbito de la comunicación universitaria andaluza". Revista internacional de relaciones públicas, 4(8), 139-160. http://dx.doi.org/10.5783/RIRP-8-2014-08-139-160

Statista (2019). Promedio de minutos diarios de uso de redes sociales por los internautas en países seleccionados en enero de 2019. Recuperado de https://bit.ly/2DWIqIQ

Wang, Y. (2019). Análisis de la comunicación de las universidades españolas en Twitter en el marco de la tercera misión. Tesis Doctoral Universidad Carlos III de Madrid. 
Departamento de Periodismo y Comunicación Audiovisual. Directora Dacil Susana Herrera Damas. Fecha de defensa 2019-03-04. Disponible en https://bit.ly/2EcJh6Z

www.metricool.com

www.ninjalitics.com

www.webescuela.com. Marketing digital y business school.

Xifra Triadú, J. (2011). Manual de relaciones públicas e institucionales. Madrid: Tecnos. 